\title{
Do Global ao Local no Ensino de PLAc em Roraima: por uma formação de histórias locais na Universidade Federal de Roraima
}

\author{
Marcus Vinícius da Silva ${ }^{1}$ \\ Colégio de Aplicação da Universidade Federal de Roraima, Boa Vista, RR, Brasil
}

Cora Elena Gonzalo Zambrano ${ }^{2}$

Universidade Estadual de Roraima, Boa Vista, RR, Brasil

Resumo: O objetivo deste artigo é apresentar o panorama do ensino de Português como Língua Estrangeira/Adicional que vem sendo desenvolvido no Estado de Roraima, até a implementação de ações educacionais para o ensino de Português como Língua de Acolhimento no âmbito da Universidade Federal de Roraima, bem como refletir sobre a importância de uma formação específica para os professores que atendem a estrangeiros em situação de imigração e refúgio. Para tanto, utilizamos uma abordagem qualitativa, cujo instrumento de geração de registros foi o levantamento documental. $\mathrm{O}$ arcabouço teórico alinha-se à Linguística Aplicada e ao pensamento decolonial (MIGNOLO, 2013). Constatamos que há entraves no que diz respeito à formação específica em PLAc, embora existam medidas que estão sendo tomadas para tentar amenizar essa problemática. Sugerimos que tal formação deve passar por reflexões do PLAc global até chegar ao contexto local, analisando o perfil dos alunos e a realidade linguística da sociedade roraimense.

Palavras-chave: PLAc; Realidade local; Formação específica.

Title: From Global to Local in PLAc teaching in Roraima: for a formation of local histories at the Federal University of Roraima

Abstract: The objective of this article is to present the panorama of teaching Portuguese as an Foreign Language/Additional Language that has been developed in the State of Roraima, up to the implementation of educational actions for the teaching of Portuguese as a Host Language within the Federal University of Roraima, as well as reflecting on the importance of specific educational background for teachers serving foreigners in situations of immigration and refuge. For that, we used a qualitative approach, whose instrument of generating records was the documentary survey. The theoretical framework is in line with Applied Linguistics and decolonial thinking (MIGNOLO, 2013). We found that there are obstacles with regard

\footnotetext{
1 Doutorando em Linguística pelo Programa de Pós-Graduação em Linguística e Língua Portuguesa da Universidade Estadual Paulista Júlio de Mesquita Filho - UNESp-Araraquara. Professor Efetivo do Magistério Federal do Ensino Básico, Técnico e Tecnológico do Colégio de Aplicação da Universidade Federal de Roraima CAp/UFRR. ORCID http://orcid.org/0000-0003-3907-3277. E-mail: marcus.silva@ufrr.br.

2 Mestra em Letras (UFRR). Doutoranda pelo Programa de Pós-Graduação em Estudos Linguísticos da Universidade Federal de Minas Gerais - UFMG. Professora Efetiva de Magistério Superior do Curso de Letras da Universidade Estadual de Roraima - UERR. ORCID http://orcid.org/0000-0001-7617-2704. E-mail: coragonzalo@gmail.com.
} 
to specific educational background in PLAc, although there are measures being taken to try to resolve this issue. We suggest that such educational background should go through reflections of the global PLAc until it reaches the local context, analyzing the profile of the students and the linguistic reality of Roraima society.

Keywords: PLAc; Local reality; Specific Educational background.

\section{Considerações Iniciais}

A partir do ano de 2015, aproximadamente, o estado de Roraima passou a sofrer um forte processo migratório de cidadãos venezuelanos, devido à grave crise econômica e social que assola o país vizinho. Tal situação tem ganhado amplo destaque, principalmente, pelos números estatísticos de solicitações de refúgio (SIMÕES et al., 2017), o que ocasionou a criação de ações educacionais para o ensino de português como língua não materna, com a finalidade de atender a demanda espontânea de sujeitos em situação de refúgio e oriundos de imigração forçada ${ }^{3}$ interessados em aprender a língua portuguesa.

O número de solicitações de refúgio de venezuelanos no Brasil cresceu exponencialmente nos últimos anos, passando de 829, em 2015, para 7.600, em junho de 2017 (SIMÕES et al., 2017). Segundo informações do Fundo das Nações Unidas para a Infância (UNICEF), entre 2015 e maio de 2019, o Brasil recebeu cerca de 178 mil solicitações de refúgio e de residência temporária de imigrantes venezuelanos ${ }^{4}$. Para acolher estruturalmente essa população imigrante no estado, 11 abrigos oficiais foram criados em Roraima, sendo 9 na capital Boa Vista e 2 na cidade de Pacaraima 5 .

De acordo com Zambrano (2019), apesar de a língua portuguesa e a língua espanhola serem línguas românicas próximas, originárias do tronco linguístico latino, a língua portuguesa é considerada distante da realidade desses imigrantes. Assim, diversos cursos de português para estrangeiros têm sido abertos e oferecidos por instituições públicas e privadas, tais como os da Universidade Federal de Roraima (doravante UFRR), com o intuito de amenizar esse transtorno linguístico e cultural da chegada ao Brasil.

No entanto, tal oferta esbarra em entraves relacionados à formação específica do professor para atender uma nova perspectiva no ensino de português, o Português como Língua de Acolhimento (doravante PLAc). De acordo com Lopez (2016), a língua de acolhimento não representa apenas um sistema de comunicação, mas passa a ser um elemento para a defesa pessoal dos sujeitos deslocados forçados quando chegam a um país de língua e cultura diferente.

Diante de tal situação, o objetivo deste artigo é apresentar o panorama do ensino de

\footnotetext{
${ }^{3}$ É o tipo de imigração sem espontaneidade, que ocorre por motivos externos e não por uma motivação pessoal.

${ }^{4}$ A informação está disponível em: https://www.unicef.org/brazil/crise-migratoria-venezuelana-no-brasil>. Acesso em 18 de maio de 2020.

${ }^{5}$ Os abrigos são administrados pelas Forças Armadas do Brasil, em parceria com a Agência da Organização das Nações Unidas (ONU) para Refugiados (ACNUR), disponível em <https://www.unicef.org/brazil/crise-migratoriavenezuelana-no-brasil>. Acesso em 18 de maio de 2020.
} 
Português como língua Estrangeira (PLE) / Língua Adicional (PLA) ${ }^{6}$ que vem sendo desenvolvido no Estado de Roraima, até a implementação de ações educacionais para o ensino de Português como Língua de Acolhimento (PLAc) no âmbito da Universidade Federal de Roraima (UFRR), bem como refletir sobre a importância de uma formação específica para os professores que atendem estrangeiros em situação de refúgio, como é o caso dos venezuelanos, pensando em uma perspectiva decolonial, que considere as especificações desse espaço fronteiriço e desses sujeitos.

Em relação à abordagem metodológica deste trabalho, cabe salientar que se trata de um estudo qualitativo (DENZIN; LINCOLN, 2006), cujo instrumento de geração de registros foi o levantamento documental, com análise da lista dos projetos de extensão cadastrados na Diretoria de Extensão da UFRR, da ementa de uma disciplina do curso de Letras, dentre outros. Nosso arcabouço teórico-metodológico segue as postulações da Linguística Aplicada Indisciplinar (MOITA LOPES, 2006) e Transgressiva (PENNYCOOK, 2006), em consonância com as teorias decoloniais (MIGNOLO, 2013).

Sendo assim, na primeira seção, apresentamos, brevemente, a constituição do estado de Roraima e sua tríplice fronteira, para que possamos compreender melhor o contexto linguístico da região. Posteriormente, explanamos acerca dos cursos de português como língua adicional/estrangeira junto com a situação de Roraima enquanto receptor de imigrantes venezuelanos, o que fez surgir a nova subárea Português como Língua de Acolhimento no estado.

Em outra seção, debatemos algumas implicações teóricas e epistemológicas diante desse novo contexto de ensino/aprendizagem de línguas. Para isso, foi necessário trazer à baila reflexões oriundas dos Estudos Decoloniais, em uma perspectiva advogada pela Linguística Aplicada, para compreender essa proposta de implementação de ensino de português como forma de acolhimento. Logo em seguida, discutimos os entraves educacionais da formação do professor de língua portuguesa para atuar nessa demanda social de acolhimento - a qual tem origem no aumento exponencial dos processos migratórios transnacionais - bem como apresentamos e analisamos as ações educacionais desenvolvidas pela UFRR que visam atender o ensino de português.

\section{O Estado de Roraima e sua Tríplice Fronteira}

Para entendermos melhor o complexo fluxo migratório transnacional que vem assolando o estado de Roraima, torna-se importante apresentarmos, brevemente, a constituição do estado de Roraima e sua tríplice fronteira, localizada ao extremo norte do Brasil.

\footnotetext{
${ }^{6}$ Neste trabalho, optamos por manter as duas nomenclaturas mais usadas pela literatura sobre ensino de línguas, sem fazer distinção entre elas, embora saibamos que muitos autores preferem o tradicional Português como Língua Estrangeira (PLE), enquanto outros, defendem o Português como Língua Adicional (PLA), principalmente, para se distanciar da dicotomia entre nativo e estrangeiro. Na UFRR, são usadas as duas nomenclaturas.
} 
O estado de Roraima ${ }^{7}$ é composto por uma tríplice fronteira trilíngue - Brasil, Venezuela, República Cooperativa da Guiana - sendo conhecida como a última fronteira brasileira, localizada ao extremo norte do país, e que, por vezes, é o estado mais desconhecido (SOUZA, 2008). Vejamos a figura 1 para que possamos compreender um pouco mais dessa tríplice fronteira linguística e cultural:

Figura 1 - Mapa Fronteira Tríplice do Estado de Roraima ${ }^{8}$

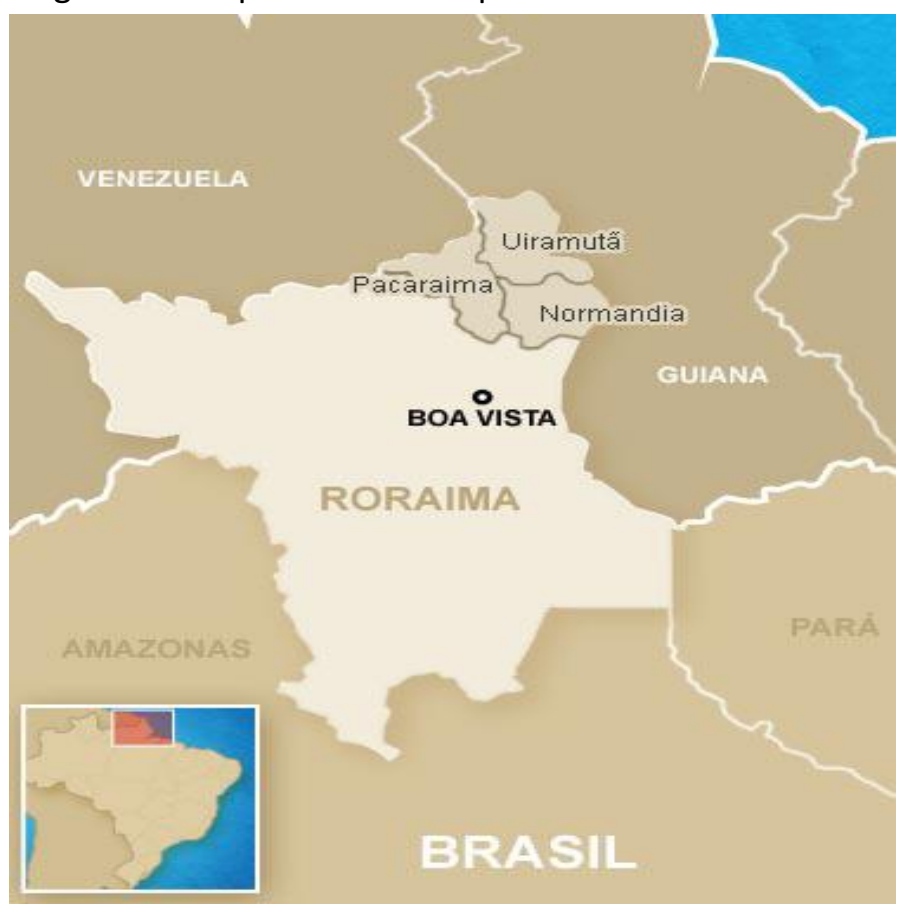

Fonte: g1/GLOBO.

A partir do mapa, é perceptível que o estado de Roraima está localizado na posição setentrional ao extremo norte do Brasil e faz fronteira com os estados do Amazonas, Pará e com os países República Bolivariana da Venezuela e República Cooperativa da Guiana. Sendo assim, pode-se dizer que a realidade de Roraima se constitui em meio ao multi/plurilinguismo, tendo em vista a complexa constituição cultural e linguística desse espaço fronteiriço.

O território geográfico de Roraima concentra distintas etnias de povos indígenas que falam mais de dez línguas diferentes, pertencentes às famílias linguísticas Caribe, Aruwak e Yanomami. De acordo com a pesquisa desenvolvida em 2019, pelo Instituto Socioambiental e o Instituto do Patrimônio Histórico e Artístico Nacional (IPHAN) ${ }^{9}$, as línguas Caribe faladas em Roraima são sete: Macuxi, Taurepang, Ingarikó, Patamona, Waimiri-Atroari, Ye'kwana e WaiWai. Cabe destacar, ainda, que o estudo detectou a existência não apenas de quatro, como era conhecido nas pesquisas anteriores, mas seis línguas distintas da família Yanomami:

\footnotetext{
${ }^{7}$ O estado de Roraima foi criado em 5 de outubro de 1988, com a promulgação da atual Constituição Federal.

${ }^{8}$ Disponível em: http://g1.globo.com/Noticias/Brasil/foto/0,14645699-EX,00.jpg. Acesso: 26 jun. 2020.

${ }^{9}$ As pesquisas com os dados do Instituto Socioambiental estão veiculadas em matéria disponível no site https://www.socioambiental.org/pt-br/noticias-socioambientais/iphan-reconhece-importancia-da-diversidadelinguistica-yanomami. Acesso: 26 de jun. 2020.
} 
Yanomami, Sanöma, Ninam, Yanomam, Ỹaroame, Yãnoma. Já, a língua Wapichana é a única representante da família linguística Aruwak falada em Roraima.

Com relação às línguas estrangeiras/adicionais na educação básica, Braz (2010) nos aponta que, embora o estado de Roraima seja constituído por uma tríplice fronteira trilíngue - Brasil, Venezuela e Guiana, no que tange ao processo de ensino/aprendizagem de línguas na escola, o espanhol representa uma língua de prestígio, visto que historicamente o Brasil mantém relações comerciais e políticas muito estreitas com a Venezuela (BRAZ, 2010, p. 01).

Além do contato nas fronteiras, Santos (2013) argumenta que a imigração fronteiriça transnacional no estado tem se intensificado, principalmente, pela entrada de imigrantes pertencentes a outros países do continente, com maior incidência para imigração venezuelana que tem aumentado exponencialmente nos últimos anos em decorrência da crise políticofinanceira que se instalou no país em meados de 2009.

Sendo assim, a forte presença dos imigrantes no estado de Roraima, principalmente, na capital Boa Vista, tem impulsionado ações de políticas linguísticas ${ }^{10}$ que contemplem a diversidade linguística e cultural de constituição desse espaço, com especial atenção para ações educacionais voltadas para o ensino de português como língua estrangeira/adicional e, posteriormente, de português para acolhimento, como veremos na próxima seção.

\section{Do PLE/PLA ao Português como Língua de Acolhimento na UFRR}

No Brasil, é perceptível o aumento considerável de investigações sobre ensino de Português como Língua Estrangeira/Adicional (PLE/PLA) em diferentes espaços e realidades, não só do Brasil, como também de outros países, com o processo de internacionalização da língua portuguesa. Esse fato se deve, principalmente, pela implementação de políticas linguísticas de ampliação das áreas de PLE/PLA e pela criação e oficialização do Certificado de Proficiência de Língua Portuguesa para Estrangeiros (CELPE-BRAS), promovido pelo Ministério de Educação (MEC), o que colaborou significativamente com a abertura de cursos em instituições públicas e privadas no Brasil.

Barbosa e Freire (2017) argumentam que, embora haja uma grande demanda por cursos de PLE/PLA no Brasil, ainda é escasso o número de instituições de nível superior, tanto públicas como privadas, em que há oferta de cursos de PLE/PLA para a comunidade. Nesse sentido, os autores elucidam, ainda, que mesmo nos cursos de Letras não é tão comum encontrar na grade curricular disciplinas relacionadas às discussões de ensino/aprendizagem de português como língua estrangeira/adicional, o que cria entraves relacionados à formação desses profissionais.

Diante do cenário de implementação de políticas linguísticas de ensino de português no estado de Roraima, a UFRR criou, em 2007, o curso de Português para Estrangeiros, por meio do Núcleo de Línguas Estrangeiras (NUCELE) da instituição (ZAMBRANO, 2019), que tem sido

\footnotetext{
${ }^{10}$ De acordo com Calvet (2007), a política linguística é uma maneira de intervir e gerenciar conflitos originários de diferentes usuários das línguas - ou também uma maneira de mobilizar relações de poder por meio do uso das línguas em determinados contextos históricos e sociais.
} 
oferecido até os dias atuais.

Assim, por um lado, a UFRR recebe a demanda espontânea de estrangeiros interessados no aprendizado de português, bem como também possui cursos específicos para atender aos estudantes dos convênios internacionais, tais como o Programa de Estudante-Convênio de Graduação (PEC-G) ${ }^{11}$. Por outro lado, a instituição também começou a atender pessoas em situação de refúgio oriundas da imigração forçada, a partir de 2017, com cursos específicos para esse novo público; o que vem contribuindo para a instauração de novas políticas e perspectivas no ensino de português para falantes de outras línguas (PFOL).

Nesse contexto, é importante destacar que o número de solicitações de refúgio de venezuelanos no Brasil cresceu exponencialmente nos últimos anos (SIMÕES et al., 2017), especialmente, quando nos referimos ao estado de Roraima - estado brasileiro vizinho à Venezuela - principal porta de entrada da imigração venezuelana no Brasil. Vejamos alguns dados estatísticos de solicitações de refúgio por estados brasileiros que corroboram essa informação:

Figura 2 - Solicitações de Reconhecimento da Condição de Refugiado por Estado em 2018

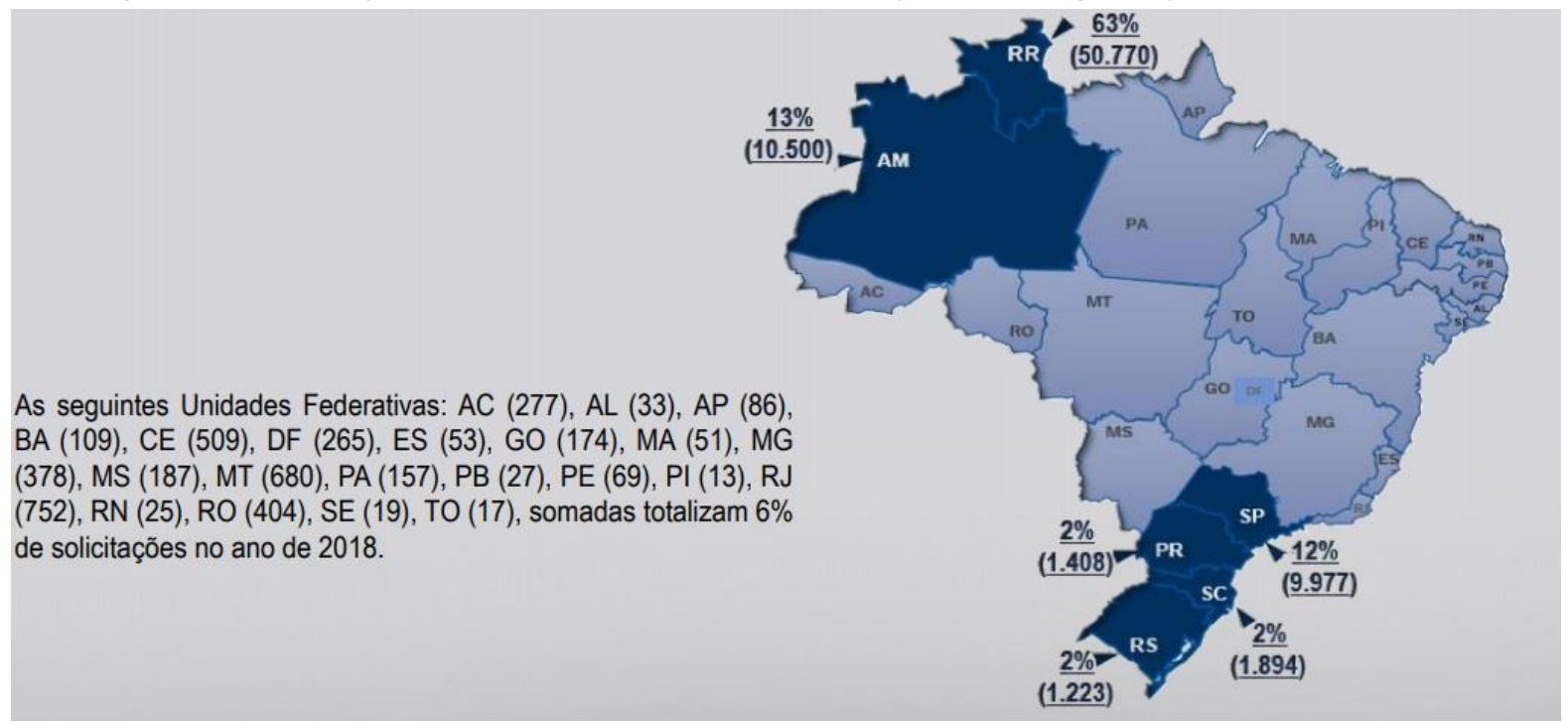

Fonte: Polícia Federal

Conforme evidenciado na figura acima, em 2018, Roraima foi o estado com maior índice de solicitação de refúgio no Brasil, correspondendo a $63 \%$ das solicitações nacionais, aproximadamente 50.770 solicitações, o que deixa claro o movimento migratório transnacional de venezuelanos para o Brasil e as novas demandas por cursos de PLE/PLA no estado. Vejamos a próxima figura que corrobora essa explanação.

\footnotetext{
${ }^{11}$ O Programa de Estudantes-Convênio de Graduação (PEC-G) foi criado oficialmente em 1965 pelo Decreto no 55.613 e, atualmente é regido pelo Decreto no 7.948. O programa tem como objetivo oferecer a estudantes de países em desenvolvimento com os quais o Brasil mantém acordo educacional, cultural ou científico-tecnológico a oportunidade de realizar seus estudos de graduação em Instituições de Ensino Superior (IES) brasileiras.
} 
Figura 3 - Solicitações de Reconhecimento da Condição de Refugiado recebidas de venezuelanos (2011 - 2018)

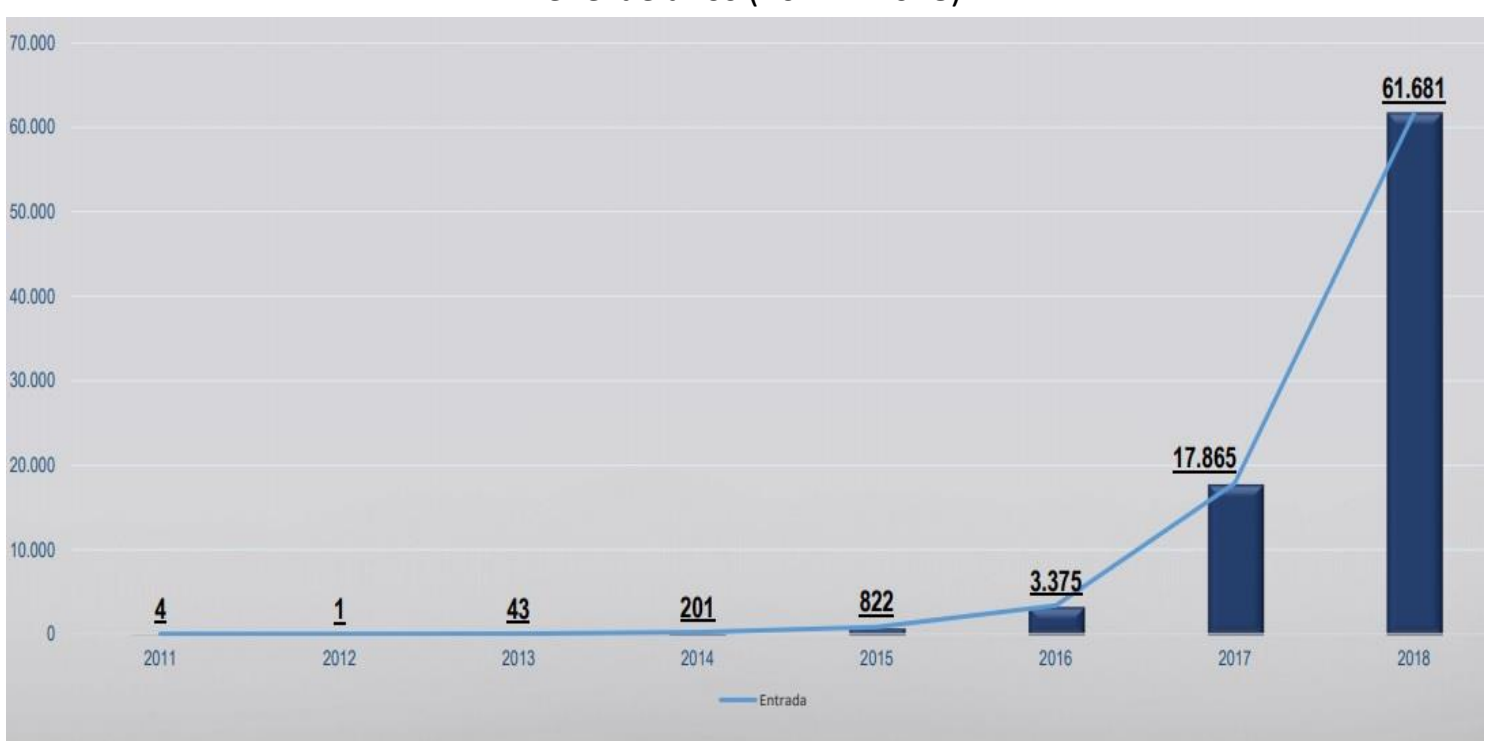

Fonte: Polícia Federal

De acordo com os dados apresentados pela Polícia Federal, entre 2011 e 2018, houve um aumento considerável de números de solicitações de refúgio de imigrantes venezuelanos no Brasil, passando de 4 em 2011, para 61.68 em 2018. Outrossim, Zambrano (2019) nos relembra que, em 2017, segundo dados do relatório de refugiados apresentado pelo Ministério da Justiça ${ }^{12}$, Roraima tornou-se o estado com maior número de solicitações de refúgio, ultrapassando, inclusive, o estado de São Paulo, que historicamente sempre liderou as estatísticas de pedidos no Brasil.

É nesse contexto de aumento exponencial do número de solicitações de refúgio no Brasil, sobretudo, no estado de Roraima, que começa a surgir no cenário universitário roraimense a nomenclatura Português como Língua de Acolhimento (PLAc) ${ }^{13}$, por meio da palestra da Profa. Dra. Lúcia Barbosa (UNB), na UFRR, em 2017. A palestra proferida pela professora pode ser considerada um divisor de águas na difusão da nova perspectiva para o ensino de português para refugiados em Roraima, com uma proposta que contempla essa nova dimensão social, no sentido de domínio profissional, dos direitos sociais e da integração temporária ou permanente ao país de acolhimento (ZAMBRANO, 2019).

Silva e Costa Júnior (2020) pontuam que, segundo o mapeamento realizado em 2015 pelo Instituto de Pesquisa Econômica Aplicada (IPEA), um dos maiores obstáculos para os refugiados no Brasil, dentre outros fatores, é a aprendizagem de uma nova língua. Cabe destacar, porém, que, muitas das vezes, essa nova língua não foi escolhida para ser aprendida, como é o caso dos imigrantes em situação de refúgio. Vejamos quadro construído por Silva e

\footnotetext{
12 Esse relatório do Ministério de Justiça está disponibilizado em: www.folhabv.com.br/noticia/PF-recebeu-56mil-pedidos-de-regularização-de-venezuelanos/42052. Acesso em 22 de junho de 2020.

${ }^{13}$ O PLAc é uma subárea do português como língua adicional/estrangeira, direcionada a pessoas em situação de vulnerabilidade social, oriundas de imigração forçada.
} 
Costa Júnior (2020, p. 135) que exemplifica melhor as problemáticas enfrentadas pelos imigrantes/ refugiados segundo as instituições, a sociedade civil e os próprios sujeitos.

Quadro 1 - Principais dificuldades enfrentadas pela população imigrante

\begin{tabular}{|cccc|}
\hline & $\begin{array}{c}\text { Segundo as } \\
\text { instituições }\end{array}$ & $\begin{array}{c}\text { Segundo a } \\
\text { sociedade civil }\end{array}$ & $\begin{array}{c}\text { Segundo os próprios } \\
\text { imigrantes }\end{array}$ \\
\hline Saúde & $5,26 \%$ & $2,70 \%$ & Não informado \\
Educação & $1,58 \%$ & $3,80 \%$ & Não informado \\
Moradia & $10,53 \%$ & $9,78 \%$ & Não informado \\
Trabalho & $10,53 \%$ & $13,04 \%$ & $20,63 \%$ \\
Documentação & $10,53 \%$ & $11,96 \%$ & $13,98 \%$ \\
Informação & $9,47 \%$ & $5,43 \%$ & $2,15 \%$ \\
Idioma & $16,84 \%$ & $16,34 \%$ & $21,74 \%$ \\
Discriminação & $7,74 \%$ & $8,73 \%$ & $5,91 \%$ \\
Financeiras & $3,16 \%$ & $1,63 \%$ & $5,91 \%$ \\
Subsistência & $3,16 \%$ & $1,09 \%$ & $5,38 \%$ \\
Acesso a serviços & Não informado & Não informado & $16,24 \%$ \\
Outros & $20,52 \%$ & $25,50 \%$ & $8,06 \%$ \\
\hline
\end{tabular}

Fonte: Adaptação feita a partir de Silva e Costa Júnior (2020)

De acordo com o quadro acima, tanto as instituições como a sociedade civil e os próprios imigrantes/refugiados destacam a aprendizagem da língua portuguesa como a principal problemática quando chegam ao Brasil, visto que a barreira linguística é um dos desafios principais no que se refere à adaptação a uma sociedade de acolhimento.

Considerando essas novas demandas em relação ao ensino de português, podemos afirmar que na UFRR começa a se pensar em uma nova perspectiva de ensino com o viés de acolhimento. O primeiro curso de Português pensando e oficializado nessa nova perspectiva de acolhimento foi oferecido pelo Projeto Acolher ${ }^{14}$. O projeto, dentre outros objetivos, visa oferecer aulas de português para refugiados em Roraima, e conta com a colaboração de acadêmicos de diferentes graduações, bem como da comunidade em geral. Outrossim, o Programa Idiomas Sem Fronteiras (ISF), em $2018^{15}$, também passou a ofertar o curso de Português para Refugiados, aberto à comunidade externa, que foi ministrado por um acadêmico do curso de Letras da UFRR (ZAMBRANO, 2019).

No entanto, essas ações de ensino de português direcionadas ao público imigrante careciam de uma formação específica, embora houvesse capacitações de curto tempo para os monitores, faltava uma formação mais ampla na área de PLE/PLA e PLAc; também era necessário discutir e refletir sobre esse novo viés para o ensino de português como acolhimento em Roraima, que contemplasse as especificidades do estado, tema que

\footnotetext{
${ }^{14}$ Esse projeto surgiu graças a um acordo com a Agência da Organização das Nações Unidas para Refugiados (ACNUR), por meio da Cátedra Sergio Vieira de Mello (CSVM).

${ }^{15}$ O Programa de Idiomas Sem Fronteiras (ISF), desde 2017, já ofertava o curso de "Leitura e Produção de Textos em Português, destinado aos docentes, funcionários e acadêmicos estrangeiros" (ZAMBRANO, 2019, p. 22).
} 
discutiremos nas próximas seções.

\section{Perspectiva Decolonial e suas contribuições para o PLAc}

Em um mundo cada vez mais global, a convivência entre diversas línguas faz parte do cotidiano da maioria das pessoas, embora haja línguas mais prestigiadas e outras de menor status social. Porém, em contextos de diversidade linguística, como é o caso do estado de Roraima e sua tríplice fronteira, além das questões de formação relacionadas ao âmbito global, é preciso também pensar e refletir nas histórias locais (MIGNOLO, 2013) que devem ser levadas em consideração quando se instauram e oficializam políticas linguísticas para o ensino/aprendizagem de línguas.

$\mathrm{Na}$ perspectiva dos estudos decoloniais, a obra Histórias locais/projetos globais: decolonialidade, conhecimentos subalternos e pensamento liminar, do filósofo argentino Walter Mignolo, traz uma discussão acerca dos conhecimentos subalternos. Para o autor, junto com a expansão da civilização e das línguas globais, houve a transformação das histórias locais, foi assim que surgiu a mundialização, segundo ele, sendo a outra cara da globalização; dentro dessas histórias locais estão contempladas as de origem hegemônica e as subalternas. Contudo, nas fronteiras dos pares mundialização/globalização e modernidade/colonialidade começam a surgir novas formas de conhecimento.

Para Mignolo (2018), a colonialidade é a fase mais escura da modernidade, pois em nome da tão desejada vida moderna, continuamos sendo colonizados em vários âmbitos: como na economia, na geração de conhecimentos e na educação. Quijano (2005), por sua vez, cunhou o termo "colonialidade do poder" que, segundo o autor, gera dominação de um povo sobre outro nos diversos setores sociais e é uma derivação do colonialismo. Tais autores fazem parte de um grupo de pensadores latinoamericanos que estimulou a expansão do pensamento crítico, questionando a hegemonia do "Norte Global" e buscando visibilizar outras vozes através de epistemologias outras capazes de decolonizar os saberes, as culturas, as artes, as sexualidades, a educação, etc. Em diálogo com o chamado "Giro Decolonial", estudos como o de Boaventura de Sousa Santos (2010) defendem as Epistemologias do Sul, não exatamente de autores do Sul no sentido geográfico, mas olhando para o Sul, para aqueles que foram subalternizados pela colonialidade/modernidade.

Retomando a questão das línguas, Mignolo (2013) faz uma crítica às antigas epistemologias de ordem ocidental, sempre ligadas a apenas uma língua colonial e a um território hegemônico, que dominaram, por muito tempo, as religiões, a ciência, a economia e a organização social. Por isso, o autor propõe o pensamento liminar (fronteiriço), o espaço que nos permite pensar e viver entre línguas, ressaltando as características locais.

Para o teórico supracitado, a língua como sistema não é importante, visto que a fala e a escrita são consideradas estratégias de manipulação na interação social. E para evitar a manipulação mediante o ensino de PLAc, devemos deixar de lado a visão de língua como estrutura e a concepção de que a língua portuguesa é o único idioma nacional do Brasil. Assim, ao pensar o acolhimento por meio da língua, é importante ressaltar que não é a língua que define quem é incluído ou não como cidadão na sociedade brasileira. 
É nesse ponto específico que entra a história local de Mignolo (2013), pois nessa perspectiva a nação é apenas mais uma versão da história. No caso de Roraima, uma história local permeada pela convivência de diversas línguas: indígenas nacionais e transnacionais, europeias (espanhola, inglesa e portuguesa) e de sinais (LIBRAS e LSV/Língua de Sinais Venezuelana). Desse modo, o PLAc em Roraima deve ser contextualizado levando em consideração a realidade do estado, não pode mais seguir a ideologia do Estado-Nação no qual surgiu, isto é, no sistema eurocêntrico, a partir do programa Portugal Acolhe, desenvolvido pelo governo português.

Nesse sentido, devemos pensar na imigração como parte da integração global que, consequentemente, nos faz ressignificar as relações entre línguas e territórios, bem como as relações culturais que se transformam em transculturais. Assim, por meio da Linguística Aplicada Indisciplinar e Transgressiva (MOITA LOPES, 2002; PENNYCOOK, 2006), problematizamos as concepções de ensino de português em Roraima e refletimos sobre a perspectiva de PLAc global até chegar ao PLAc local, analisando o perfil dos nossos alunos e a realidade local da nossa sociedade, inclusive, levando em consideração toda a diversidade linguística e cultural constitutiva de Roraima, isto é, as duas fronteiras internacionais, a composição populacional oriunda de distintas regiões do Brasil, as línguas de sinais, bem como as línguas indígenas que por aqui circulam, dentre outros fatores.

Desse modo, é necessário pensar o ensino de PLAc com uma proposta de interculturalidade epistêmica, nos moldes definidos por Walsh (2005), como novas relações de poder, saber e ser, as quais questionam disciplinas e estruturas dominantes ao buscar formas de pensar diferente, por meio do pensamento fronteiriço. É com essas reflexões sobre o ensino de línguas que devemos pensar em propostas de ensino/aprendizagem de PLAc em Roraima.

Ruano e Cursino (2019) ressaltam a importância de ensinar PLAc a partir do contexto dos alunos, tomando como base a história e a cultura deles e de seus países. Na mesma perspectiva, Zambrano (no prelo) defende a necessidade de aproveitar o letramento social de cada aluno, respeitando os letramentos locais ${ }^{16}$, assim como a diversidade dos deslocados forçados.

Nesse sentido, é importante compreender os imigrantes como pessoas iguais a nós, que possuem conhecimentos a serem compartilhados, não como subalternos que estão na sala de aula apenas para aprender aquilo que os professores acham que é mais urgente para sua inserção na sociedade. Isto é, deixar de lado o discurso da falta que Diniz e Neves (2018) definem como:

Um discurso essencialista e totalizador que, a partir de uma posição etnocêntrica, significa certos sujeitos por aquilo que supostamente 'não são', 'não fazem', 'não

\footnotetext{
${ }^{16}$ Os letramentos locais são aqueles que já fazem parte do cotidiano das pessoas, mesmo antes da imposição do letramento escolar. Para Street (2014), as práticas de letramento não devem se limitar ao letramento escolar padronizado, o que ele chama de letramento autônomo, mas devem estar relacionadas à prática social dos alunos, deixando de lado a suposta superioridade do letramento escolar em detrimento de outros tipos de letramento.
} 
sabem' e 'não conhecem' apagando, consequentemente, suas vivências, suas agências, seus saberes e seus conhecimentos - que, cabe ressaltar, não integram os repertórios daqueles que os enxergam como um conjunto de lacunas a serem preenchidas (2018, p. 100-101).

Portanto, o PLAc em Roraima deve valorizar o imigrante, suas vivências e seus saberes, ao ressaltar as histórias locais dos sujeitos oriundos de uma imigração de crise, que trazem consigo um letramento local para compartilhar e transformar as relações por meio da interculturalidade epistêmica. Isso significa incentivar o ensino da língua portuguesa no sentido decolonial, sem subalternizar nenhuma das línguas inseridas no contexto sociolinguístico complexo do estado. Mas para isso, os professores devem receber uma formação específica que contemple mais do que questões linguísticas e metodológicas, tema que debatemos na próxima seção.

\section{Ensino de PLAc e a Formação Profissional Docente na UFRR}

Conforme diversos autores já apontaram, o ensino de PLAc no Brasil vem sendo oferecido graças à iniciativa de voluntários (AMADO, 2013; LOPEZ, 2016; MIRANDA \& LOPEZ, 2019) que, nem sempre, possuem a formação docente profissional em Letras e, muito menos, em PLE/PLA e em PLAc. No estado de Roraima, essa problemática formativa específica não é diferente, tendo em vista que a demanda pelo ensino/aprendizagem de português aumentou consideravelmente nos últimos anos por causa da imigração transnacional forçada e em massa, principalmente, dos venezuelanos.

No contexto roraimense, apenas existiam os cursos de PLE/PLA oferecidos por duas instituições de nível superior, a UFRR e a Universidade Estadual de Roraima (UERR). O curso oferecido pela primeira IES era voltado para os alunos intercambistas e estrangeiros em geral; já, o curso da segunda instituição, destinava-se à população moradora das cidades fronteiriças Pacaraima/Brasil e Santa Elena de Uairén/Venezuela. Contudo, a demanda social fez surgir novas iniciativas e projetos de cursos, uns com auxílio de voluntários, outros com parcerias e financiamentos, mas todos sem experiência nem formação na área específica de PLAc (ZAMBRANO, 2019).

Cabe destacar, ainda, no tocante à falta de formação específica desse profissional de Letras, que apenas quatro Instituições de Ensino Superior do Brasil oferecem o curso de graduação em Letras Português com habilitação em Língua Adicional ou Língua Estrangeira: a Universidade de Brasília (UnB), a Universidade Federal da Bahia (UFBA), a Universidade Nacional de Integração Latinoamericana (UNILA) e, a mais recente, a Universidade Estadual de Campinas (UNICAMP) que, desde 2017, oferece Letras com habilitação em Português Segunda Língua / Língua Estrangeira (DINIZ \& NEVES, 2018).

Nos últimos anos, diante da emergência de necessidade formativa específica para o ensino/aprendizagem de PLE/PLA e PLAc, outras instituições de nível superior da área de Letras vêm incorporando, em suas grades curriculares, disciplinas voltadas para tal área, a título de exemplo podemos citar: a Universidade Federal de Minas Gerais (UFMG) e, no âmbito 
de Roraima, a própria Universidade Federal de Roraima (UFRR), a qual analisaremos e destacaremos mais adiante.

Contudo, Miranda e Lopez (2019) elucidam que, no que corresponde ao ensino de PLAc, há uma omissão por parte do Governo Federal no desenvolvimento de políticas públicas destinadas aos imigrantes em situação de refúgio, como por exemplo, na estruturação do processo de ensino/aprendizagem de PLAc, no sentido de valorização da formação e do trabalho dos professores, com a finalidade de deixar de lado o sistema de voluntariado. Para as autoras, além da formação docente específica, é necessária uma formação cidadã que seja capaz de empoderar os imigrantes, no sentido atribuído por Maher (2007), que perpassa pela interculturalidade e pela educação do entorno.

Outrossim, Miranda e Lopez (2019, p. 24) pontuam que, na formação docente em PLAc, devem ser valorizados os saberes dos professores em formação, pois "os saberes emergentes das práticas profissionais desses professores poderiam, portanto, contribuir para sua própria formação e para a formação dos outros participantes desse mesmo processo". Além disso, as autoras apontam a necessidade de reflexão crítica por parte dos profissionais da área de PLA/PLAC.

$\mathrm{Na}$ mesma linha de ideias, Zambrano (no prelo) segue a prática educativo-crítica defendida por Freire e afirma que os professores voluntários, na maioria das vezes, sem formação específica, passam pelo processo de aprendizagem mútuo, conscientes de que devem aprender com a prática ou a partir dela; em outras palavras, é uma formação em constante reflexão que deve passar da prática para a teoria e retornar à prática. A autora destaca também a educação linguística ampliada (CAVALVANTI, 2013) que os profissionais que se dispõem a ensinar PLAc precisam buscar, a educação defendida pela linguística aplicada crítica, que ultrapassa as barreiras do monolinguismo, passando pelo multi e plurilinguismo, até chegar à transliguagem e ao letramento crítico. Tal educação se preocupa, ainda, pela promoção de políticas linguísticas para grupos marginalizados e pela educação do entorno, isto é, por uma formação muito além das questões linguísticas, para nós, seria uma formação de histórias locais em projetos globais. Entretanto, concordamos com Miranda e Lopez (2019) ao afirmar que o processo de formação em PLAc se tornará realidade quando houver maior investimento em políticas públicas para a formação desses profissionais, mediante a institucionalização da área de PLA e PLAc nas Instituições de Ensino Superior do Brasil.

$\mathrm{Na}$ Universidade Federal de Roraima, nos últimos anos, podemos perceber a implementação de algumas ações educacionais com a finalidade de proporcionar uma formação em PLE/PLA/PLAc, para a qualificação dos professores envolvidos nos cursos oferecidos em Roraima. Além das palestras e capacitações promovidas pelo Projeto Acolher, apontadas por Zambrano (2019), outros programas da UFRR começaram a oferecer cursos voltados para a formação na área.

Diante da realidade de professores voluntários sem formação, em 2019, o Programa de Pós-Graduação em Letras da Universidade Federal de Roraima (PPGL/UFRR) realizou uma ação de política linguística/formativa para que discentes do curso de Letras da UFRR e 
membros da comunidade pudessem se capacitar para o ensino de PLE/PLAc. Esse curso foi chamado de "Formação para Professores de PLE/PLAc"17, e foi ministrado pela Profa. Dra. Maria D'Ajuda, a qual estava como professora visitante nacional sênior na instituição. O curso foi realizado todas as segundas-feiras, terças-feiras e sextas-feiras, das oito às doze horas, com carga horária de trinta horas.

Ademais, outra ação de política linguística desenvolvida pelo PPGLL/UFRR foi um curso de "Redação em Língua Portuguesa para Refugiados e Imigrantes" ${ }^{18}$, sob coordenação e orientação da Profa. Dra. Julia Martins, do curso de Letras - Português / Inglês da UFRR. O Curso foi realizado em 2019, com carga horária de trinta horas. É importante destacar que, a ação foi proposta em virtude do lançamento do edital no 053/2019 da Comissão Permanente de Vestibular (CPV/UFRR), específico para refugiados/imigrantes que desejam ingressar em cursos de nível superior na UFRR.

Desse modo, percebemos que a UFRR tem implementado ações de políticas linguísticas/formativas, no sentido de viabilizar caminhos para amenizar os problemas de ensino e formação decorrentes da nova demanda de cursos de PLE/PLA e, principalmente, PLAc, ocasionadas pelo processo de migração transnacional em massa que vem acontecendo no estado nos últimos anos.

No entanto, como é perceptível, essas ações educacionais ainda carecem de um maior planejamento linguístico, visto que é preciso pensar em uma política linguística formativa permanente e a longo prazo, que considere as especificidades linguísticas e culturais da localidade e dos imigrantes forçados, para propor reflexões epistemológicas decoloniais que possam atravessar os projetos globais até chegar às histórias locais na formação profissional dos professores de línguas em Roraima.

Além dessas políticas linguísticas formativas, diversos setores da UFRR também se mobilizaram para debater a questão migratória que assola o estado e, alguns ofereceram projetos de extensão direcionados à comunidade imigrante em situação de refúgio. Cabe esclarecer, em um primeiro momento, que as iniciativas para se discutir a imigração transnacional, bem como as ações educacionais para abertura de cursos de PLAc foram realizadas graças aos professores e acadêmicos voluntários que ficaram sensibilizados com esse movimento migratório forçado do país vizinho.

Vejamos as ações cadastradas na Diretoria de Extensão (DIREX) da UFRR, entre 2016 e 2019:

\footnotetext{
${ }^{17}$ Informação disponível em: http://ufrr.br/ppgl/index.php?option=com content\&view=article\&id=439:cursode-formacao-para-professor-ple-plac\&catid=25\&Itemid=298\&lang=pt. Acesso: 03 jul. 2020.

18 Informação disponível em: http://ufrr.br/ppgl/index.php?option=com content\&view=article\&id=454:cursode-redacao-em-lingua-portuguesa-para-refugiados-e-imigrantes\&catid=18\&ltemid=102\&lang=pt. Acesso: 03 jul. 2020.
} 
Quadro 2 - Ações de extensão cadastradas na DIREX/UFRR

\begin{tabular}{|c|c|}
\hline Título do Projeto & Unidade Responsável \\
\hline $\begin{array}{c}\text { Curso - Português para Estrangeiros } \\
\text { Refugiados Políticos }\end{array}$ & Comissão Permanente de Vestibular \\
\hline $\begin{array}{c}\text { Evento - A Questão Migratória em Roraima: } \\
\text { quais soluções possíveis }\end{array}$ & Coordenação do Curso de Administração \\
\hline $\begin{array}{c}\text { Evento - I Congresso Brasileiro sobre } \\
\text { Migrações e Refugiados }\end{array}$ & Instituto de Ciências Jurídicas \\
\hline $\begin{array}{c}\text { Evento - Workshop Internacional sobre Crise } \\
\text { Migratória em Roraima: Água, Higiene e } \\
\text { Saneamento }\end{array}$ & Departamento de Engenharia Civil \\
\hline Projeto - Apoio a Refugiados em Roraima & Curso de Antropologia \\
\hline $\begin{array}{l}\text { Projeto - Conéctate: conectividade livre e } \\
\text { gratuita para pessoas em situação de } \\
\text { refúgio/migração e comunidade da UFRR }\end{array}$ & Departamento de Relações Internacionais \\
\hline $\begin{array}{c}\text { Projeto - Direito Internacional dos } \\
\text { Refugiados }\end{array}$ & $\begin{array}{c}\text { Programa de Pós-Graduação em Sociedade e } \\
\text { Fronteiras }\end{array}$ \\
\hline $\begin{array}{l}\text { Projeto - Imigração e Mercado de Trabalho: } \\
\text { Oportunidade no Cenário Brasileiro }\end{array}$ & Departamento de Secretariado Executivo \\
\hline Projeto - Português para Acolhimento & $\begin{array}{l}\text { Coordenação do Curso de Relações } \\
\text { Internacionais }\end{array}$ \\
\hline
\end{tabular}

Fonte: Adaptado de DIREX/UFRR (2019).

É perceptível, portanto, a partir da leitura do quadro II, que são poucas as ações cadastradas na DIREX referentes à imigração venezuelana: sendo três eventos com essa problemática, dois cursos de português e cinco projetos que versam sobre diferentes frentes para amenizar a problemática. Quando nos referimos às políticas linguísticas para o ensino de português - maior problemática enfrentada pelos imigrantes/refugiados, segundo Silva e Costa Júnior (2020) - vemos que o número de ações é ainda menor, apenas duas: (i) Curso de Português para Estrangeiros/Refugiados Políticos, cuja unidade responsável é a Comissão Permanente de Vestibular e (ii) Projeto de Português para Acolhimento, sendo a unidade responsável a Coordenação do Curso de Relações Internacionais.

No contexto de implementação de ações para o ensino/aprendizagem de português percebe-se que há entraves relacionados à formação dos professores que estão atuando nesses projetos, visto que a unidade responsável por tais ações linguísticas deveria ser o curso 
de Letras da UFRR; porém, como vimos, as iniciativas surgiram em outros cursos. Conforme apontado por Zambrano (2019), o curso de português oferecido pelo Projeto Acolher começou com o trabalho voluntário de acadêmicos de diversas áreas, além de pessoas externas à universidade, verificando uma ausência de profissionais da área de Letras. Posteriormente, os acadêmicos e egressos do curso Letras, alguns com experiência em PLE, uniram-se ao voluntariado do Português como Acolhimento.

Com relação à formação específica que esses acadêmicos e egressos de Letras/UFRR poderiam ter recebido, destacamos uma disciplina eletiva denominada Português - Língua Estrangeira, a qual fazia parte da grade curricular do curso desde 2009, sendo ofertada apenas duas vezes, em 2014.2 e em 2017.1. Posteriormente, com a reformulação do Projeto Pedagógico do Curso de Letras da UFRR, em 2017, a disciplina ganhou uma ementa mais ampla e passou a ser chamada de Tópicos Especiais em Português como Língua Estrangeira; incorporada à grade no segundo semestre de 2018, sendo ofertada em 2018 e em 2019, portanto, com maior frequência nesses últimos anos.

É importante relembrar que, embora a disciplina não seja obrigatória e, consequentemente, não contemple horas práticas, muitos estudantes de Letras tinham a experiência de monitoria nos cursos de português do Centro de Línguas e do curso oferecido para o PEC-G. Abaixo, disponibilizamos a ementa e o programa da disciplina Tópicos Especiais em Português como Língua Estrangeira, que atualmente vigora na grade do curso:

Quadro 3 - Disciplina de Tópicos Especiais em Português como

Língua Estrangeira da UFRR ${ }^{19}$

EMENTA

Estudo do Português como língua estrangeira, abordando metodologias, materiais didáticos, formação de professores. Comparação das características da Língua Portuguesa com as de outras línguas.

\section{PROGRAMA}

- O ensino de Português como Língua Estrangeira no Brasil e na UFRR;

- O exame Celpe-Bras: Certificado de Proficiência em Língua Portuguesa para Estrangeiros;

- Breve panorama das metodologias de ensino de Línguas Estrangeiras;

- Análise de materiais didáticos em Português como Língua Estrangeira;

-Ensino de Português como Língua Estrangeira para grupos específicos;

- Produção de materiais didáticos em Português como Língua Estrangeira.

Fonte: Adaptado de Projeto Político Pedagógico do Curso de Letras - Português - UFRR, 2017.

\footnotetext{
${ }^{19}$ A disciplina é oferecida para os cursos de Letras - Português e Espanhol; Letras - Português e Francês; Letras - Português e Inglês e Letras - Português. A ementa e o programa da disciplina estão disponíveis em: http://ufrr.br/letrasliteratura/index.php?option=com phocadownload\&view=category\&id=10\&ltemid=361. Acesso: 02 jul. 2020.
} 
É importante destacar, novamente, que a incorporação dessa disciplina na grade curricular do Curso de Letras da UFRR é um primeiro ato de política linguística formativa permanente de capacitação de professores frente aos novos desafios de ensino de português como língua estrangeira/adicional/acolhimento nesse contexto, tendo em vista os entraves educacionais relacionados à formação professional docente e diante da grande demanda ocasionada pela imigração transnacional.

Em relação à ementa da disciplina, é necessário salientar que leva em consideração alguns aspectos basilares e primordiais para o ensino de PLE, abordando desde aspectos atravessados pela constituição desse campo de estudos recentes no Brasil até aspectos metodológicos, analíticos e comparativos entre o português e outras línguas estrangeiras. Esses conteúdos elencados na disciplina poderiam atender as necessidades de formação dos profissionais da área de letras para as demandas existentes antes da imigração em massa de venezuelanos para Roraima, isto é, os cursos voltados aos estudantes intercambistas de convênios como o PEC-G e os cursos oferecidos pelo Centro de Línguas da UFRR. No sentido global, a disciplina parece contemplar a área de uma forma ampla, até com um tópico destinado ao ensino de PLE para grupos específicos; porém, não é possível perceber nenhum tema relacionado às características locais desse ensino.

Em virtude do aumento da imigração transnacional de venezuelanos em situação de refúgio ou de imigração forçada, seria necessário introduzir reflexões do ponto de vista dessa nova perspectiva de ensino/aprendizagem de português como acolhimento, de forma direcionada ao atual contexto linguístico roraimense. Nesse sentido, a nosso ver, deveria ser ofertada outra disciplina, que incluísse discussões sobre essa demanda social para o ensino de português em projetos de extensão e também na educação básica, tendo em vista o alto número de estudantes estrangeiros matriculados nas escolas públicas do estado.

Além disso, também acreditamos que tal disciplina deveria ser obrigatória na grande curricular dos cursos de Letras e suas habilitações, visto que devemos direcionar a formação de professores para o campo da Linguística Aplicada Indisciplinar (MOITA LOPES, 2006) e Transgressiva (PENNYCOOK, 2006), no sentido de viabilizar uma formação profissional dos docentes de línguas que envolva o modo de pensar e fazer por meio de problematizações a partir do seu contexto linguístico e cultural. Ou seja, é preciso pensar numa formação que proporcione reflexões oriundas das teorias decoloniais, possibilitando o pensamento liminar e a interculturalidade epistêmica.

Dessa maneira, a formação específica passaria dos projetos globais de ensino de PLE/PLA, para as histórias locais do PLAc em Roraima, levando em consideração os letramentos locais dos alunos e a diversidade linguística do estado acolhedor; o que proporcionaria, aos futuros docentes, maior capacidade para atender a demanda decorrente da imigração forçada no contexto fronteiriço do estado. 


\section{Considerações finais}

No decorrer do artigo, apresentamos a atual situação de implementação de ações educacionais voltadas para o ensino de português como língua estrangeira/adicional/ acolhimento oferecidas pela Universidade Federal de Roraima (UFRR), tendo em vista o forte processo migratório transacional que se intensificou durante a última década no estado e que demanda políticas específicas para o atendimento dessa problemática linguística local.

Nesse sentido, também trouxemos à baila discussões que atravessam a formação específica para os professores que atendem a estrangeiros em situação de refúgio e imigração forçada, discutindo e problematizando aspectos relacionados à formação docente que leve em consideração reflexões do contexto global para uma realidade local no processo de ensino/aprendizagem de português, bem como discussões sobre a formação específica do profissional docente de línguas, para atender a essa nova perspectiva educacional de acolhimento que se instaurou e oficializou com o contexto de imigração transacional.

Após as análises das ações educacionais implementadas pela UFRR para atenuar essa problemática social, linguística e histórica, percebemos que, ainda são escassos os projetos de extensão cadastrados junto à Diretoria de Extensão (DIREX) da UFRR, especificamente no período analisado, de 2016 a 2019, que tratam de ações linguísticas para atender esse público de refugiados, originários de uma crise humanitária.

Além disso, vimos que o curso de Letras da UFRR, com o objetivo de atenuar a problemática da formação profissional docente no que tange os cursos de PLE, incorporou, na grade curricular das suas habilitações, uma disciplina eletiva de Português como Língua Estrangeira, com carga horária de sessenta horas teóricas. No entanto, por ser optativa, não oferece horas práticas, o que poderia inviabilizar a formação teórico-prática para o futuro professor.

Vale destacar que, quando pensamos em uma formação mais ampla para os profissionais que estão recebendo o público imigrante, seja nos cursos de extensão ou na educação básica, faz-se necessário a inclusão de uma disciplina específica em Português como Língua de Acolhimento, que siga as postulações da Linguística Aplicada Transgressiva e Indisciplinar, capaz de proporcionar reflexões oriundas das teorias decoloniais e possibilitando o pensamento liminar e a interculturalidade epistêmica. Desse modo, a área de PLE/PLA/PLAc estará institucionalizada na UFRR, oferecendo uma formação específica para atender a atual demanda do estado; passando pelos projetos globais até chegar aos projetos de histórias locais.

Outrossim, é perceptível que houve ações políticas formativas pontuais desenvolvidas pela Programa de Pós-Graduação em Letras da Universidade Federal de Roraima (PPGL/UFRR) que tentaram trazer par às discussões do ensino de português nesse novo viés social de acolhimento, tanto possibilitando a formação de professores para trabalharem com essa perspectiva, como também um curso de redação de português para refugiados que desejam cursar nível superior na UFRR.

Portanto, há ações de políticas linguísticas/formativas sendo pensadas e desenvolvidas 
pela UFRR, no sentido de amenizar os problemas de ensino e formação decorrentes da grande demanda de cursos de PLE/PLA e, recentemente, de PLAc no estado de Roraima. Entretanto, defendemos que os caminhos da formação específica não são apenas por meio de disciplina optativa e teórica ou cursos de formação ofertados de forma isolada e pontual.

No nosso entendimento, os caminhos para enfrentar a problemática linguística e formativa em PLE/PLA/PLAC no estado carecem de implementação, de fato, de políticas linguísticas/formativas voltadas para a educação linguística ampliada (CAVALCANTI, 2013) dos profissionais de letras, com maior atenção para a inclusão de disciplinas que proporcionem uma formação mais humana, mais decolonial e específica para nosso contexto.

\section{Referências}

AMADO, R. S. O ensino de português como língua de acolhimento para refugiados. Revista da SIPLE, Brasília, ano 4, n. 2, s. p., 2013.

BARBOSA, J. B.; FREIRE, D. de J. Formação de professores e ensino de Português como Língua Adicional. Estudos Linguísticos, v. 46, n. 2, p. 593-602, 2017. https://doi.org/10.21165/el.v46i2.1721

BRAZ, E. S. Línguas e identidades em contexto de fronteira Brasil/Venezuela. Dissertação (Mestrado) Universidade Estadual de Campinas - Instituto de Estudos da Linguagem. Programa de Pós-Graduação em Linguística. Campinas, 2010.

CALVET, L. As Políticas Linguísticas. São Paulo: Parábola, 2007.

DENZIN, N. K.; LINCOLN, Y. S. O planejamento da pesquisa qualitativa: teorias e abordagens. Porto Alegre: Artmed, 2006.

DINIZ, L. R.; NEVES, A. O. Políticas linguísticas de (in)visibilização de estudantes imigrantes e refugiados no ensino básico brasileiro. Revista $X$, v. 13, n. 1, p. 87-110, 2018. https://doi.org/10.5380/rvx.v13i1.61225

LOPEZ, A. P. A. Subsídios para o planejamento de cursos de português como língua de acolhimento para imigrantes deslocados forçados no Brasil. 2016. 260 f. Dissertação (Mestrado em Linguística Aplicada) - Faculdade de Letras, Universidade Federal de Minas Gerais, Belo Horizonte, 2016.

MAHER, T. M. A educação do entorno para a interculturalidade e o plurilinguismo. In: KLEIMAN, A. B.; CAVALCANTI, M. C. (Orgs.) Linguística Aplicada - suas faces e interfaces. Campinas, SP: Mercado de Letras, 2007. p. 255-270.

MIGNOLO, W. Historias locales/diseños globales: colonialidad, conocimientos subalternos y pensamiento fronterizo. Ediciones Akal, S. A, 2013.

MIRANDA, Y. C. LOPEZ, A. P. Considerações sobre a formação de professores no contexto de ensino de português como língua de acolhimento. In: FERREIRA, L. C. et al. (orgs). Língua de Acolhimento: experiências no Brasil e no mundo. Mosaico Produção Editorial: Belo Horizonte, 2019. p. 17-40.

MOITA LOPES. L. P. (org.). Por uma Linguística Aplicada Indisciplinar. São Paulo: Parábola, 2006. 
PENNYCOOK, A. Uma linguística aplicada transgressiva. In: MOITA LOPES, L. P. (org.). Por uma linguística aplicada indisciplinar. São Paulo: Parábola, 2006. p. 67-84.

QUIJANO, A. Colonialidade do poder, Eurocentrismo e América Latina. Buenos Aires: CLACSO, 2005.

RUANO, B.P.; CURSINO, C. Multiletramentos e o second space no ensino aprendizagem de PLAc: da teoria à prática. In: FERREIRA, L. C. et al. (orgs). Língua de Acolhimento: experiências no Brasil e no mundo. Mosaico Produção Editorial: Belo Horizonte, 2019. p. 41-62.

SANTOS, A. R. As representações sociais da fronteira e dos migrantes estrangeiros na mídia impressa roraimense. Boa Vista, Editora UFRR, 2013.

SILVA, F. C.; JÚNIOR COSTA, E. O ensino de Português como Língua de Acolhimento (PLAC) na linha do tempo dos estudos sobre o Português Língua Estrangeira (PLE) no Brasil. Revista Horizontes De Linguística Aplicada, v. 19, n. 1, p. 125-143, 2020.

SIMÕES et. al. À guisa de introdução: Imigração venezuelana no Brasil. In: SIMÕES, Gustavo da Frota (Org.) Perfil sociodemográfico e laboral da imigração venezuelana no Brasil. Curitiba: CRV, 2017. p. 09-12.

SOUSA SANTOS, B. Para além do pensamento abissal: das linhas globais a uma ecologia dos saberes. In: SANTOS, B.; MENEZES, M. P. M. Espistemologias do Sul. Portugal: Ed. Cortez, 2010.

SOUZA, C. M. Migração e Memória: (re)interiorização e inserção social entre gaúchos residentes em Boa Vista. Espaço e Tempo, n. 33, 2008.

UFRR, Projeto Pedagógico do Curso de Licenciatura em Letras-Português, 2017. Disponível em:http://ufrr.br/letrasliteratura/index.php?option=com_phocadownload\&view=category\& $\mathrm{id}=10 \&$ Itemid=36. Acesso: 02 jul. 2020.

UFRR, Diretoria de Extensão - DIREX, 2019. Disponível em: http://prae.ufrr.br/index.php/acoes-de-extensao/apresentacao-extensao. Acesso em 02 de julho de 2020.

WALSH, K. Interculturalidad, conocimientos y decolonialidad. Signo y pensamiento. Vol. XXIV, n. 46, enero-junio, p.39-50, 2005.

ZAMBRANO, C. E. G. Português como Língua de Acolhimento em Roraima: Da falta de formação específica à necessidade social. Revista X, Curitiba, v. 14, n. 3, p. 16-32, 2019. https://doi.org/10.5380/rvx.v14i3.60942

ZAMBRANO, C. E. G. PLAc como transgressão: da formação linguística ampliada aos letramentos sociais. In: SOUZA, R. Português como Língua de Acolhimento no Brasil: práticas e perspectivas. Belo Horizonte: Editora CEFET/MG, no prelo.

Recebido em: 23/07/2020.

Aceito em: 20/12/2020. 